تقارير مؤتمرات

\title{
دورة منهجية التكامل المعرفي
}

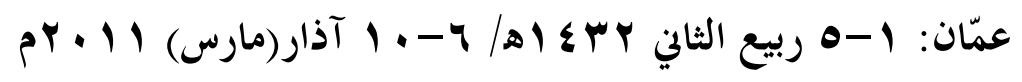

\section{أحد أبو سمك"}

نظّم المعهد العالمي للفكر الإسلامي/مكتب الأردن بالتعاون مع جامعــة العلــوم

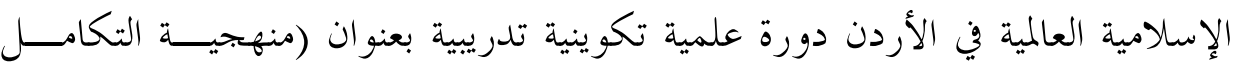

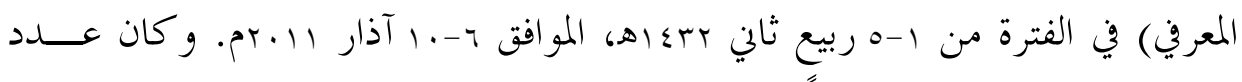

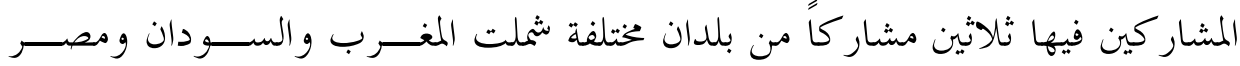

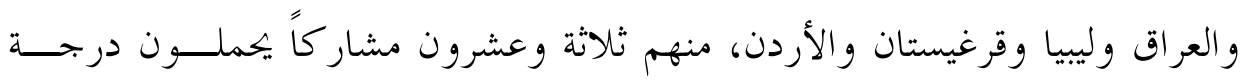

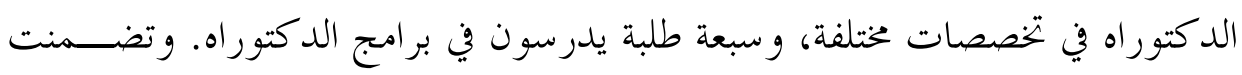

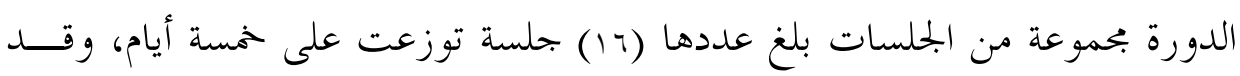

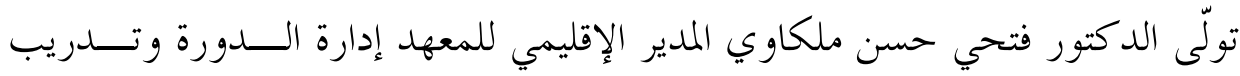
المشار كين طيلة أيام الدورة.

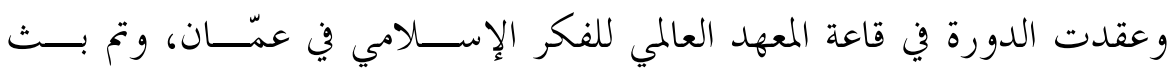

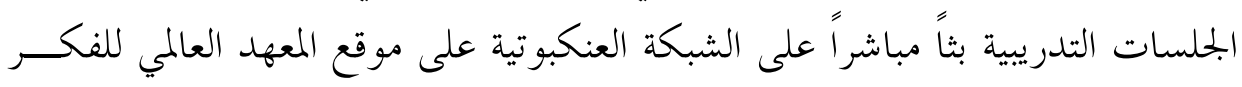

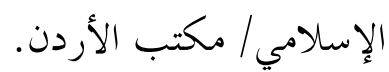
وهدفت الدورة إلى تمكين المثدر بين من امتلاك خصائص الثقافة المنهجية والـــوعي الإني

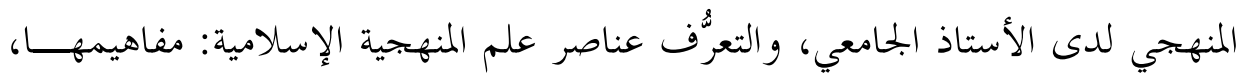

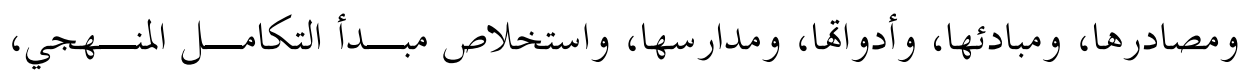

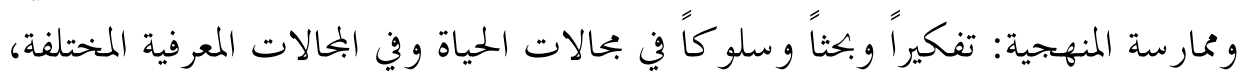

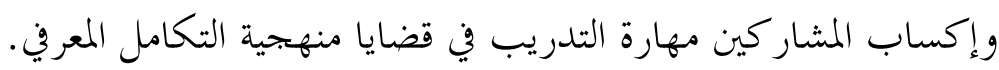

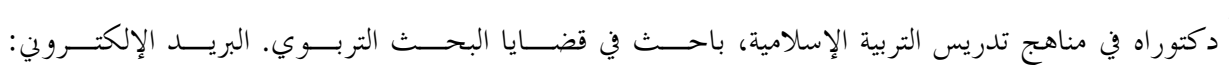
.abusamak@yahoo.com 
وكانت مواد الدورة قد أرسلت إلى المشاركين قبل موعد انعقاد الدورة بأربعــة أسابيع، وتضمنت المادة الأساسية للدورة وهي المادة التي أعدها مدير الدورة الدكتور

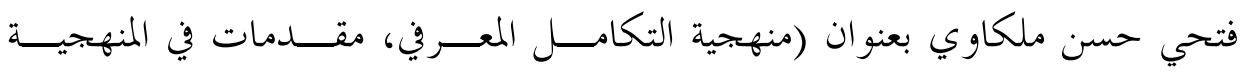

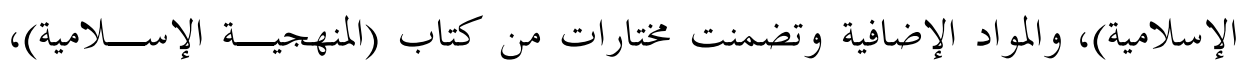

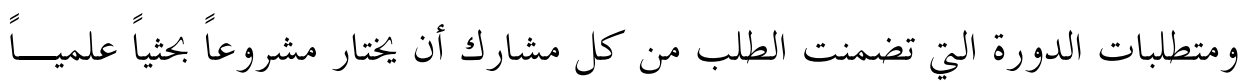

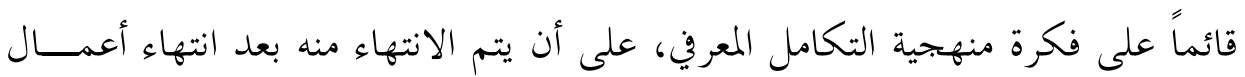

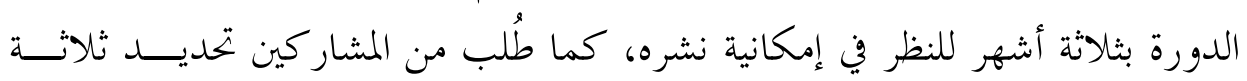

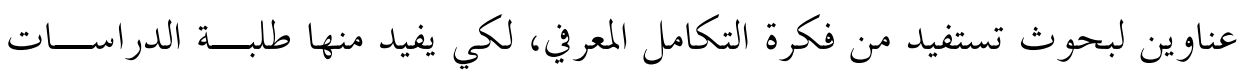
العليا. وبدأت أعمال الدورة بجلسة افتتاحية عقدت في جامعة العلوم الإسلامية العالميــة، تضمنت كلمة الأستاذ الدكتور ناجي أبو رميلة نائب رئيس جامعة العلوم الإســالامية

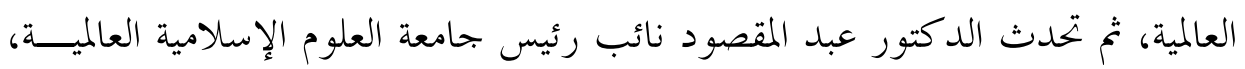
عميد كلية الدعوة وأصول الدين. وألقى الدكتور فتحي حسن ملكاوي مدير الدورة؛

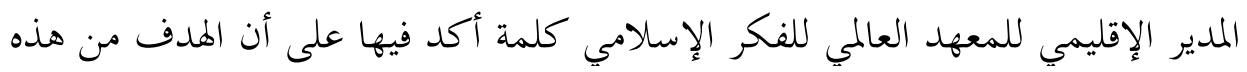

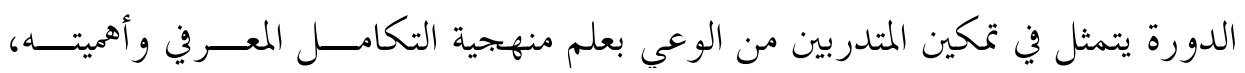

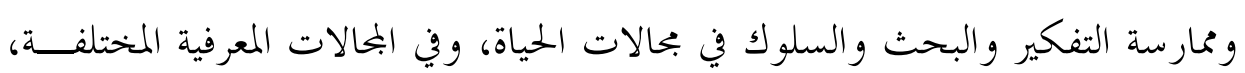

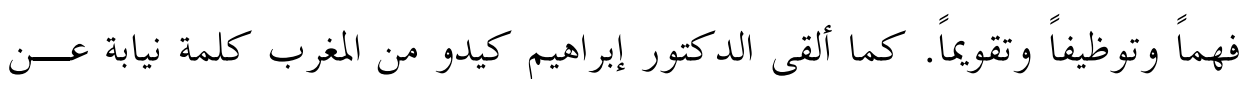

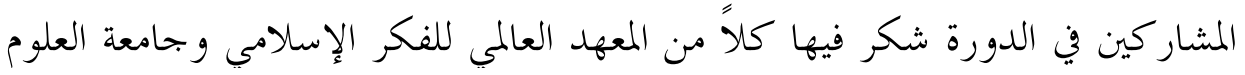

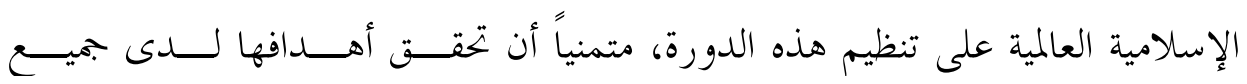
المشار كين. ومن الجدير بالذكر أن جلسات الدورة ركزت على الجانب التدريي والمناقشات

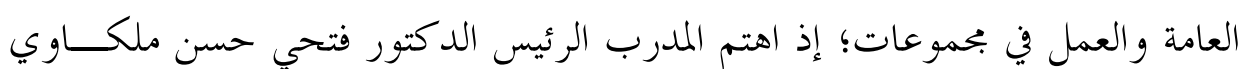

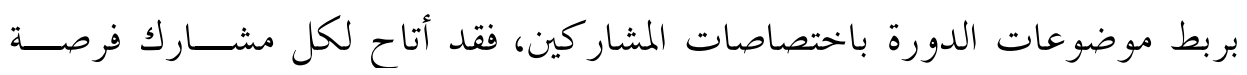

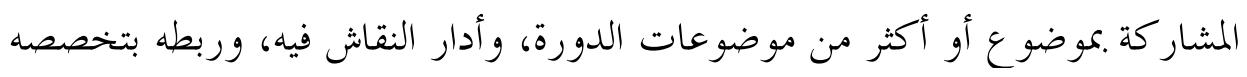




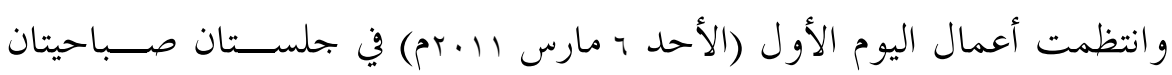

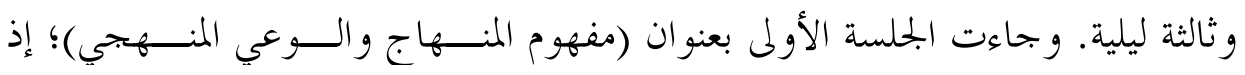

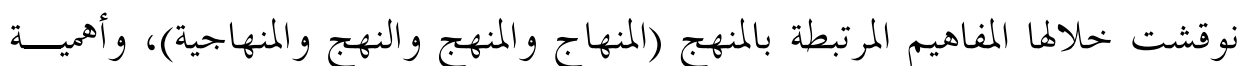

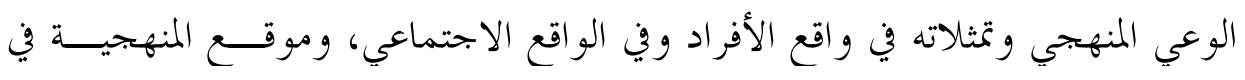
مشروع إصلاح الفكر الإسلامي.

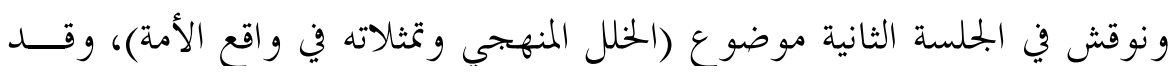

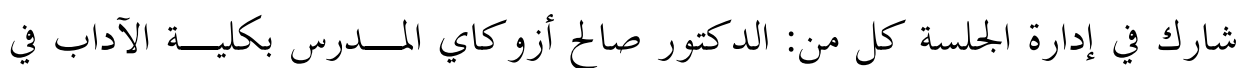

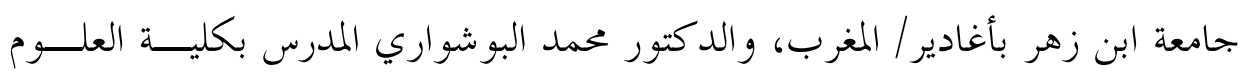

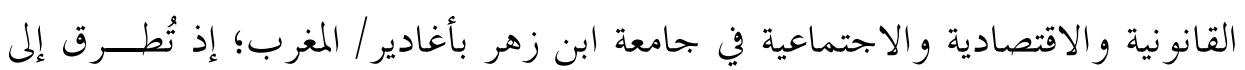

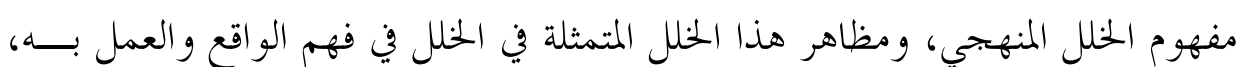

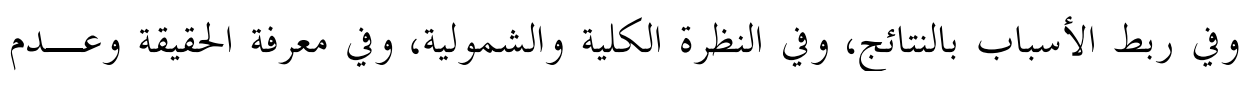
العمل .بمتضضاها.

واختتم اليوم الثدريي الأول للدورة بجلسة ليلية عقدت في فندق توليدو في عمان

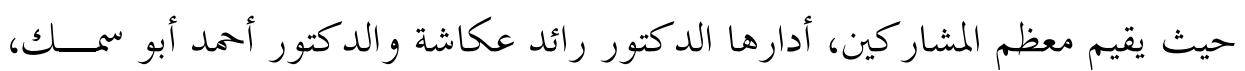

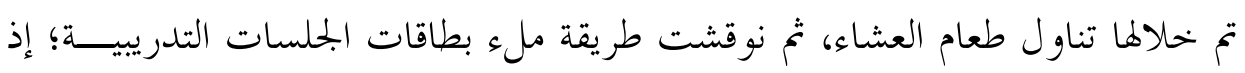

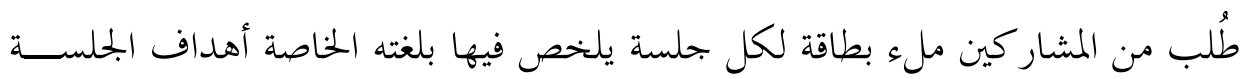

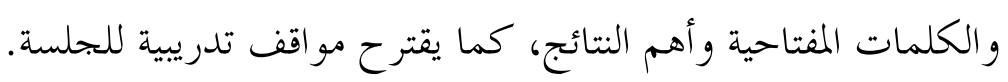

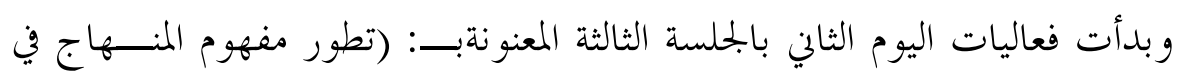

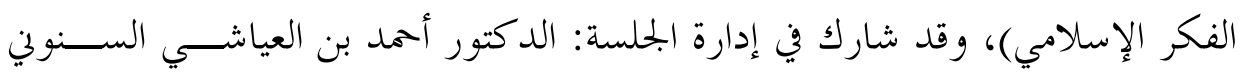

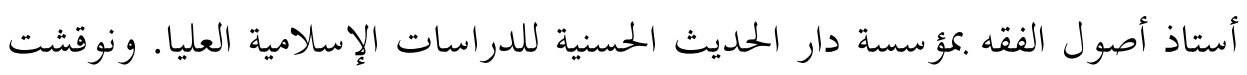

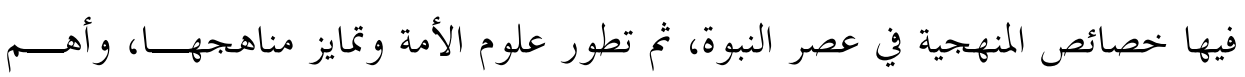

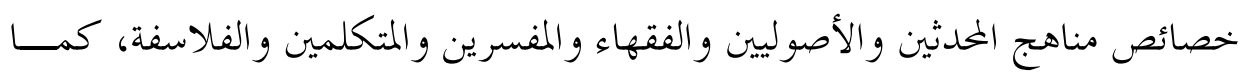
تم استخلاص لبعض الأصول المنهجية في القرآن الكريم.

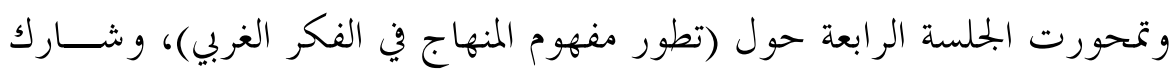

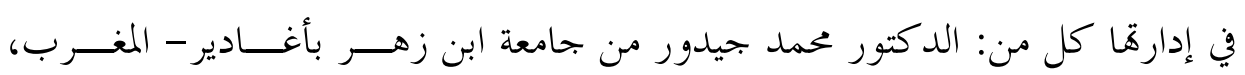


والدكتور قيس محمود حامد أستاذ فلسفة العلوم مععهد إسلام المعرفة في جامعة الجزيرة

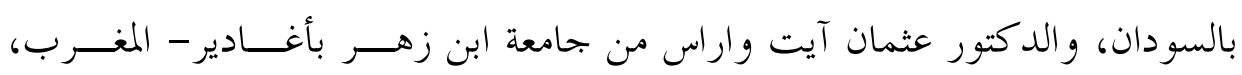

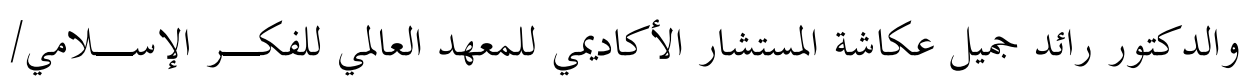
مكتب الأردن. وهدفت الجلسة إلى استخلاص المنهجية السائدة في الفكر الغــربي في

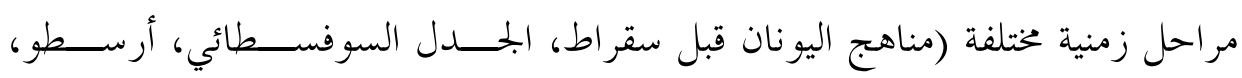
فر انسيس بيكون، رينيه ديكارت، المنهج الوضعي، الحداثة وما بعد الحماثة).

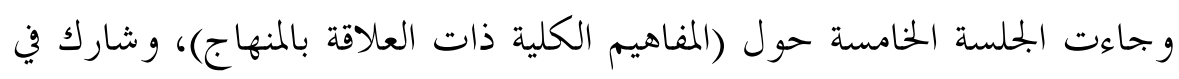

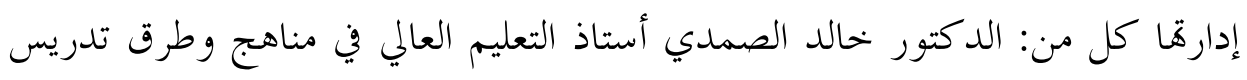

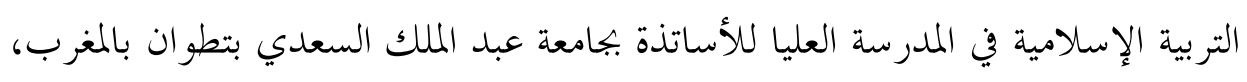

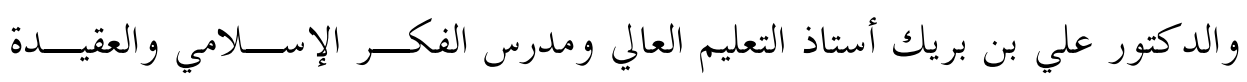

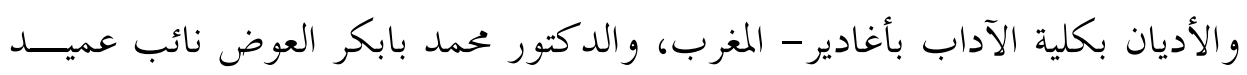

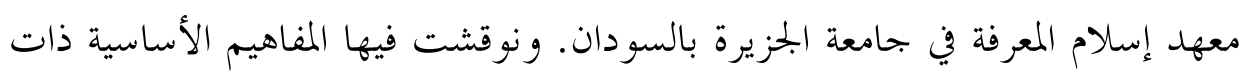

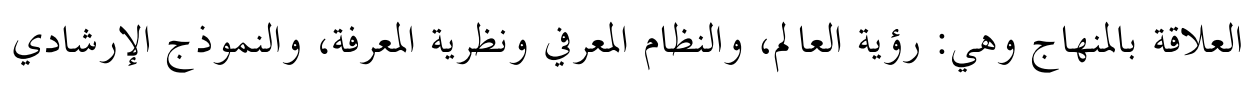

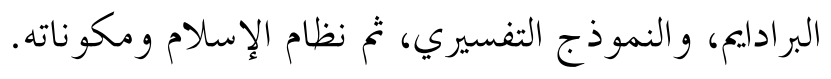

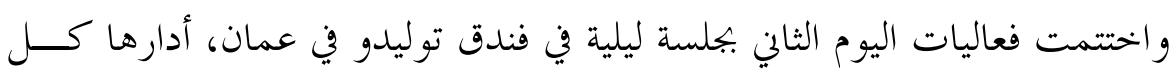

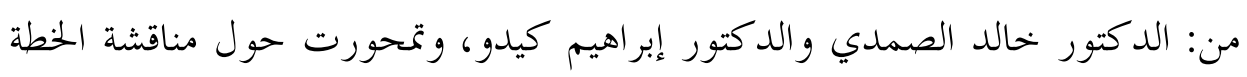
البحثية التي طُلب من المشار كين تقديمها.

وبدأت فعاليات اليوم الثالث بالجلسة السادسة المعنونة بـــ: (مصادر المنهجيــة). وشارك في إدارقا كل من: الدكتور محمد الخو الدة-كلية الآداب و العلوم الإنسانية في جامعة العلوم الإسلامية العالمية، والدكتور وليد مصطفى شاويش المدرس في قسم الفقه

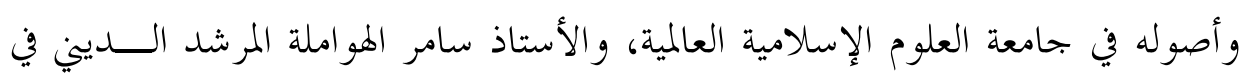

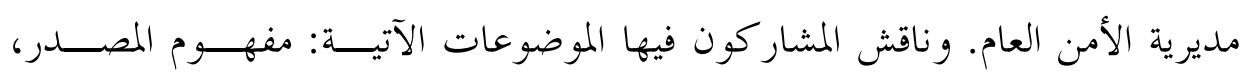

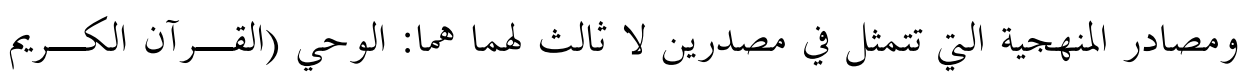

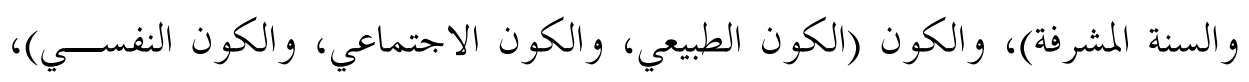
و التكامل بين مصدري المنهجية. 
وجاءت الجلسة السابعة تحت عنوان (أدوات المنهجية)، وقد شارك في إدارها كل

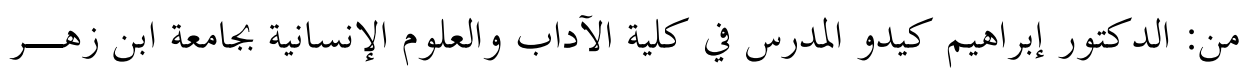

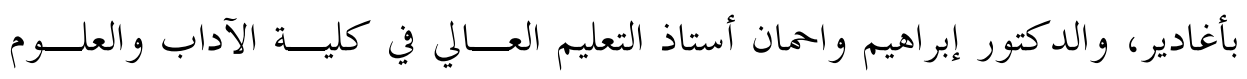

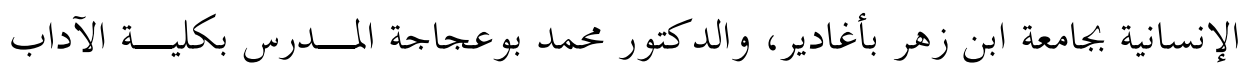

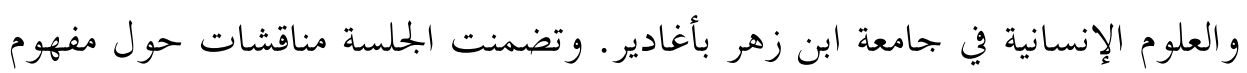

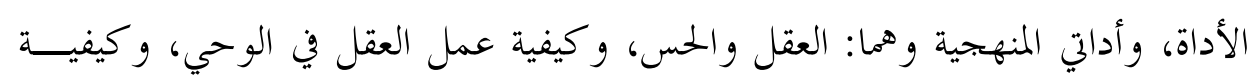

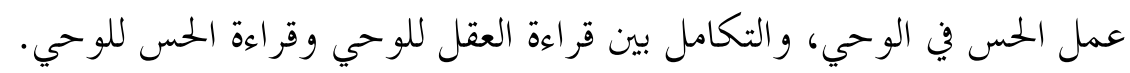

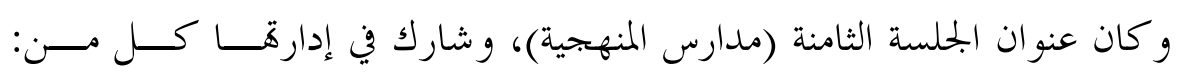

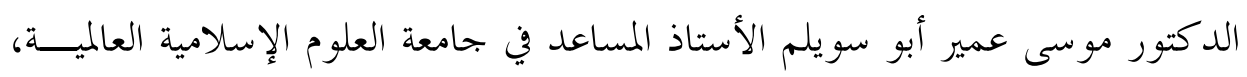

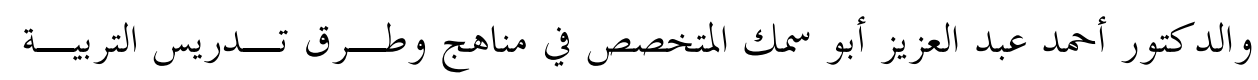

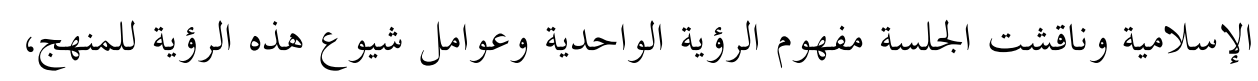

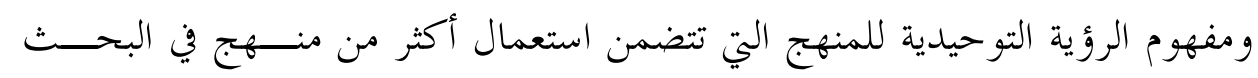

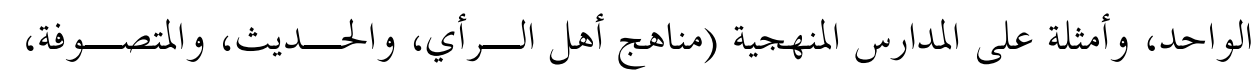

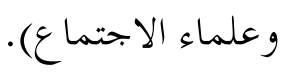
واختتمت أعمال اليوم بجلسة تدريبية ليلية في فندق توليدو بعمان، أدارها الدكتور

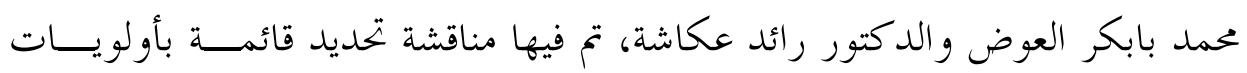
البحث في المستقبل.

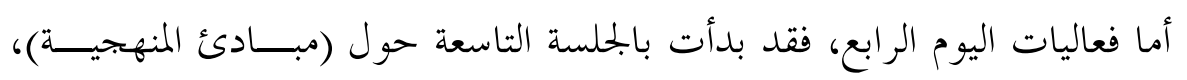

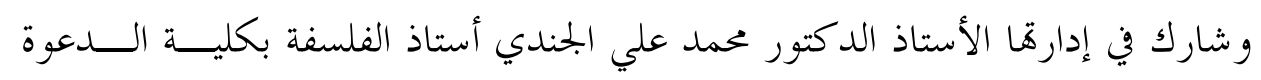

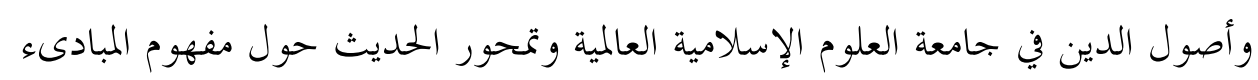

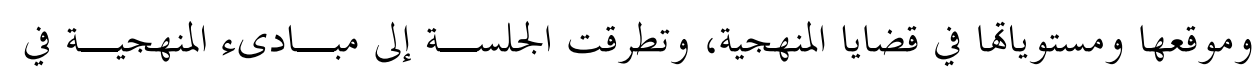

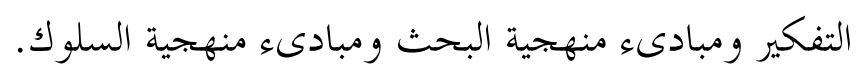

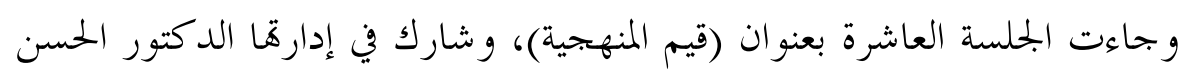

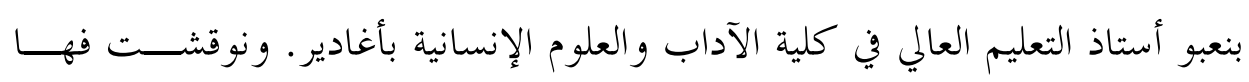




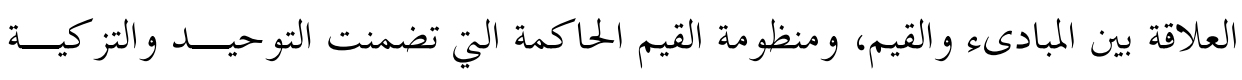
و العمر ان، وما يتفرع عن كل منها من قيم فرعية.

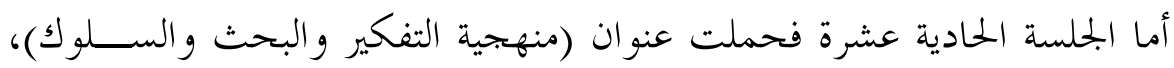

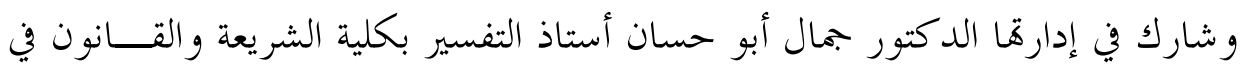

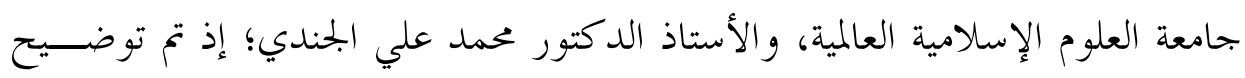

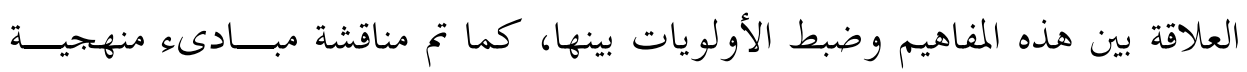

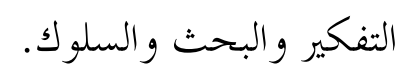
واختتمت أعمال اليوم بجلسة تدريبية ليلية في فندق توليدو، أدارها الدكتور فتحي

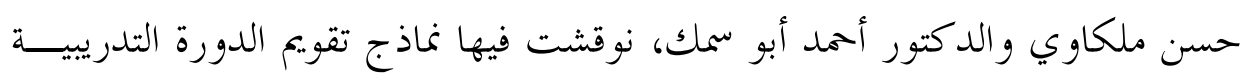
اللنتامية الكمية و النوعية. وبدأ اليوم الأخير من الدورة، بالجلسة الثانية عشرة المعنونة بـــ: (معادلة التكامل

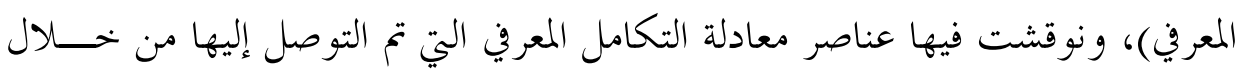
موضوعات الدورة، وقد شارك عدد كبير من المشار كين في طرح موضوعات نقاشــية حول موضوع الدورة بشكل عام.

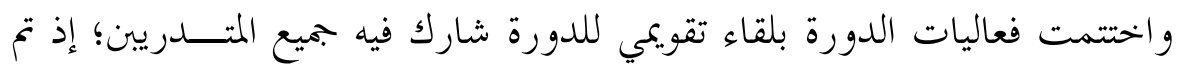

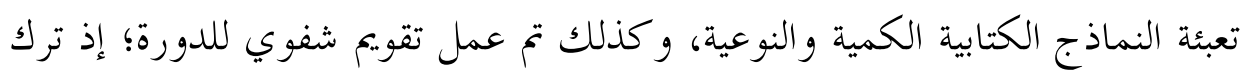

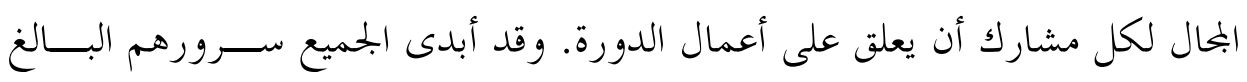

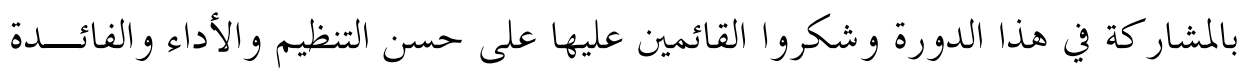

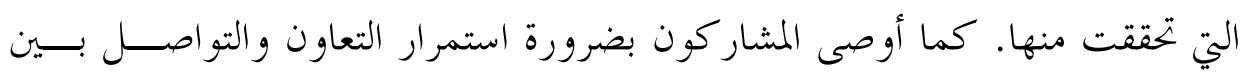

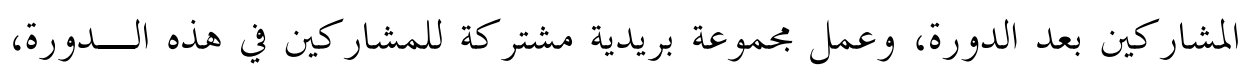

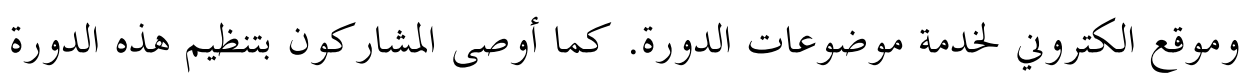

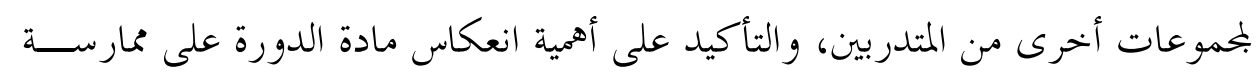
التعليم الجامعي. وفي هاية الدورة وزعت الشهادات على المشاركين. 